\title{
MUDANÇA E DESENVOLVIMENTO SOCIAL VIA ESTRATÉGIA DE SAÚDE DA FAMÍLIA: UMA ANÁLISE DAS PRÁTICAS DISCURSIVAS À LUZ DA ABORDAGEM DAS CAPACITAÇÕES
}

\author{
SOCIAL CHANGE AND DEVELOPMENT THROUGH EDUCATION AS A \\ FAMILY HEALTH STRATEGY: AN ANALYSIS OF DISCURSIVE PRACTICES \\ IN LIGHT OF THE CAPABILITY APPROACH
}

\author{
AleXandra Jochims Kruel ${ }^{1}$ e Luis Roque KLeRING ${ }^{2}$
}

Recebido em: 10/11/2012 Aprovado em: 11/06/2013

\section{RESUMO}

Até a Constituição de 1988, o Brasil possuía um sistema de saúde voltado aos trabalhadores formais, centrado na cura das doenças e na assistência aos doentes e, por meio de atendimento hospitalar, baseado na atuação do profissional médico. Com a promulgação da nova Constituição da República, o país deparou-se com uma gama de novos direitos sociais, dentre eles, o direito à saúde, como universal e como dever do Estado. Dois anos depois, em 1990, foi emitida a Lei Orgânica da Saúde (LOS), consolidando as determinações constitucionais e o Sistema Único de Saúde (SUS). No ano seguinte, em 1991, foi instituído o Programa de Agentes Comunitários de Saúde (PACS), visando ampliar o acesso ao sistema de saúde, assim como enfatizar as ações de prevenção e de promoção da saúde em nível local. Em 1994, a nova proposta de saúde foi aprofundada sob o nome de Programa de Saúde da Família (PSF). Em 1998, o modelo (ou enfoque) de atenção à saúde da família foi expandido, passando a ter uma conotação de atuação ampla, inteligente e interligada, sob a denominação de Estratégia de Saúde da Família (ESF). Nessa perspectiva, a educação para trabalhadores de saúde e para usuários tornou-se uma palavra-chave, e aliar os campos saúde e educação passou a fortalecer a saúde, não apenas como resultado ou produto de ações, mas, principalmente, como meio com grande potencialidade para articular ações e promover melhorias de qualidade de vida para além da mera ausência de doenças. Adota-se, então, no campo da saúde, um discurso vinculado à ótica de uma educação significativa, para que os usuários conheçam seus direitos e as formas de obtê-los, exercendo efetivo controle social, melhorando, assim, as suas condições de vida e a de suas comunidades. Com a finalidade de apoiar a reflexão, o presente artigo recorre à abordagem das capacitações, de Amartya Sen, que é considerada coerente e apoiadora das propostas do SUS e da ESF, ambas potencializadoras de processos de desenvolvimento em que práticas discursivas são entendidas como fala e ação, como manifestações orais, sejam elas verbais ou não.

Palavras-Chave: Estratégia de Saúde da Família; Sistema Único de Saúde; Abordagem das capacitações; Mudança social; Desenvolvimento social.

\begin{abstract}
Until the promulgation of the 1988 Constitution, Brazil's health system was geared towards formal employees, focusing on curing diseases and caring for the sick through hospital assistance provided by physicians. Following the proclamation of the new Constitution, the country faced a wide range of new social rights, including that of health as a universal right and duty of the State. In 1990, the Fundamental Health Law (Lei Orgânica da Saúde-LOS) was passed, consolidating the constitutional provisions and the Unified Health System (Sistema Único de Saúde SUS). The following year saw the implementation of the Community Health Agent Program (Programa de Agentes Comunitários
\end{abstract}

' Doutora em Administração pela Universidade Federal do Rio Grande do Sul (UFRGS), Brasil. Administradora no Grupo Hospitalar Conceição. E-mail: akruel@ghc.com.br

${ }^{2}$ Doutor em Administração pela Universidade de São Paulo (USP), Brasil. Pós-doutor em Engenharia e Gestão do Conhecimento da Universidade Federal de Santa Catarina (UFSC). Professor e pesquisador da Escola de Administração da Universidade Federal do Rio Grande do Sul (UFRGS). E-mail: lrklering@via-rs.net. 
de Saúde-PACS), aimed at expanding access to healthcare and emphasizing prevention initiative as well as health promotion at local level. In 1994, a new health proposal was launched under the name Family Health Program (Programa de Saúde da Familia - PSF) and was expanded in 1998 to include extensive, intelligent and interconnected care, becoming known as the Family Health Strategy (Estratégia de Sáude da Família - ESF). In this respect, education for health professionals and users alike has become a key-word in that combining the fields of health and education appears to strengthen the health system not only as a result or product of actions, but primarily as a means of linking initiatives and promoting improvements in quality of life beyond the mere absence of disease. Thus, healthcare has adopted an educational perspective, allowing users to be aware of their rights and how to secure them, exercising effective social control and thereby improving their living conditions and those of their communities. In support of this study, we applied Amartya Sen's capability approach since it is in line with SUS and ESF proposals; both of which enhance developmental processes in which discursive practices are understood as speech, actions and oral manifestations, whether verbal or not.

Keywords: Family Health Strategy; Unique Health System; Capabilities approach; Social change; Social development.

\section{Introdução}

Até a Constituição de 1988, pouco mais de vinte anos atrás, o Brasil possuía um sistema de saúde destinado aos trabalhadores formais, centrado na doença e a assistência aos doentes, por meio de atendimento hospitalar, baseado na atuação do profissional médico. Em 1988, com a promulgação da nova Constituição da República, o país deparou-se com uma gama de novos direitos sociais, incluído entre eles o direito à saúde, que passou a ser universal e um dever do Estado. Dois anos depois, em 1990, foi emitida a Lei Orgânica da Saúde (LOS), consolidando as determinações constitucionais e o Sistema Único de Saúde (SUS). Em 1991, foi criado o Programa Agentes Comunitários de Saúde (PACS), invertendo o foco de atenção tradicional na saúde, que passou da cura de doenças em unidades de saúde para a sua prevenção através da promoção da saúde nos domicílios e nas comunidades. Constituiu também uma experiência importante de consolidação da descentralização dos recursos do SUS. Em 1994, uma nova proposta de saúde começou a tomar vulto nacional sob o nome de Programa de Saúde da Família (PSF), como estratégia de reorganização das práticas tradicionais de trabalho e de reestruturação do modelo de atenção à saúde. A expansão da orientação, no campo da saúde, de um programa para uma estratégia de governo, com a conotação de atuação ampla, inteligente e interligada, foi instituída em 1998 (e ratificada em 2011), sob o nome de Estratégia de Saúde da Família (ESF).

Nessa nova realidade, a educação para trabalhadores de saúde e para usuários tornou-se uma palavra-chave no SUS, e aliar os campos saúde e educação passou a fortalecer a saúde não apenas como resultado ou produto de ações, mas principalmente como meio com grande potencialidade para articular ações e promover soluções, uma vez que pode gerar reflexão e discussões que levam cidadãos a buscar melhorias de qualidade de vida para além da mera ausência de doenças. O campo da saúde adota, então, um discurso vinculado à ótica de uma educação significativa, cuja intenção é modificar as representações do processo saúde-doença, tanto dos trabalhadores como dos demais cidadãos, para que estes saibam o que é preciso para a melhoria de suas condições de vida e das de suas comunidades, conheçam seus direitos e as formas de obtê-los e exerçam efetivo controle social.

De acordo com Thomas (2000), é possível pensar o desenvolvimento sob três formas distintas: a) como um ideal a ser alcançado, b) como um pro- 
cesso histórico transformador da realidade social e c) como ação de agências, abarcando instituições para o desenvolvimento, governos, organizações não governamentais, atores diversos, dentre outros. Adota-se, então, neste artigo, a concepção de que o desenvolvimento pode ser compreendido a partir da sobreposição dessas três concepções.

Para apoiar esta reflexão, recorre-se à abordagem das capacitações, de Amartya Sen (2000; 2005), a qual foi considerada aproximada às propostas do SUS e da ESF, orientadas para a mudança da realidade social. Nessa abordagem, o desenvolvimento é constituído pela eliminação de privações de liberdades substanciais, as quais limitam as escolhas e oportunidades das pessoas em exercer sua condição de agente, agindo como um processo de expansão de liberdades reais de que as pessoas desfrutam. Uma abordagem sob tal enfoque embasa-se em alguns conceitos essenciais (funcionamentos ou condições de vida, capacidades humanas, bem-estar, agência, liberdades de escolha) e permite o reconhecimento e a apreciação dos papéis das diferentes instituições e dos atores envolvidos, bem como dos valores, dos costumes e das normas sociais. Este artigo tem a intenção de refletir sobre as práticas discursivas em educação do SUS e da ESF, como potencializadoras de processos de desenvolvimento (como transformação social com vistas à melhoria das condições de vida das pessoas, famílias e sociedades, por meio de intervenção estatal e da participação da sociedade), entendendo-se práticas discursivas como constituintes da fala e da ação, manifestações orais, sejam elas verbais ou não, e refletindo-as à luz da abordagem das capacitações.

A estruturação do artigo dá-se em três seções, além da sua Introdução e das suas Considerações Finais. A primeira seção, logo após a Introdução, trata de história, trazendo um breve panorama da construção do SUS e, na sequência, da ESF, sua proposta, suas características, as atividades que desenvolve e os profissionais envolvidos, apontando, principalmente, para o agente comunitário de saúde como um ator de grande importância nesse modelo de atenção à saúde. A seção seguinte apresenta, de forma breve, as considerações principais da abordagem das capacitações, de Amartya Sen. A terceira seção traz reflexões sobre as práticas discursivas da ESF, principalmente no que diz respeito à relação entre educação e saúde, e sobre a abordagem das capacitações, visto que são propostas que se aproximam ao defenderem a capacitação das pessoas para a busca por melhores condições de vida.

\section{Contando histórias...}

\subsection{Saúde no Brasil: o Sistema Único de Saúde}

... SUS, fruto das lutas sociais por saúde, expressa em seu ideário o sonho de um sistema de saúde universal, equânime, altamente resolutivo, acolhedor, responsável e capaz de contribuir para o desenvolvimento da autonomia das pessoas e das populações para um andar a vida com mais saúde... (CECCIM, 2005, p. 979).

Até a Constituição de 1988, o Brasil possuía um sistema de saúde destinado aos trabalhadores formais. Era um sistema que não considerava a saúde como direito de cidadania, mas como necessidade de manutenção do trabalhador, para a consequente garantia da produção de bens e serviços. O sistema não incluía todos os brasileiros, e centrava-se nas doenças e na assistência aos doentes por meio de atendimento hospitalar, focado na atuação do profissional médico. Ações de cunho coletivo ou preventivo não eram prioridades, salvo em casos de endemias, que poderiam abalar de forma grave o trabalho ou a estabilidade social. 
Dez anos antes da promulgação da Constituição, em fins da década de 1970, 134 países e 67 organismos internacionais reuniram-se na Conferência Internacional sobre Cuidados Primários em Saúde, em Alma-Ata, no Cazaquistão, organizada pela Organização Mundial da Saúde (OMS) e pelo Fundo das Nações Unidas para a Infầncia (UNICEF). Naquele evento, imbuídos dos debates efetuados na Assembleia Mundial de Saúde realizada no ano anterior, denominada "Saúde para todos no ano 2000", os participantes assumiram a saúde como "um estado de completo bem-estar físico, mental e social, e não apenas a ausência de doença ou enfermidade", como um direito humano fundamental, cuja consecução em seu nível mais alto é a mais importante meta social mundial e cuja realização requer a ação de outros setores econômicos e sociais além do setor saúde (ALMA-ATA, 1978, p. 01). Esse conceito de saúde, aliás, foi definido anteriormente na Constituição da Organização Mundial de Saúde, em 1946, que considerava a saúde como o primeiro princípio básico para a felicidade, para as relações harmoniosas e para a segurança de todos os povos. Porém, o conceito não obteve fácil aceitação, principalmente, por que seus objetivos foram considerados inalcançáveis (DALLARI, 2008).

À época de Alma-Ata, partia-se da constatação de grande desigualdade no estado de saúde dos povos de países considerados desenvolvidos e subdesenvolvidos e, devido a isso, os participantes comprometeram-se com a meta de proporcionar "Saúde para todos no ano 2000". Algumas considerações foram feitas na ocasião, como meios para o alcance da meta proposta, a saber:

- criação de uma ordem econômica internacional para a redução das desigualdades;

- a responsabilização dos governos pela saúde de seus povos, por meio de medidas sociais e sanitá- rias, com o objetivo de que todos os povos do mundo pudessem atingir, até o ano 2000, níveis sociais que lhes permitissem vida social e economicamente produtiva;

- a instituição dos cuidados primários em saúde 3 como ponto chave, partindo de um espírito de justiça social;

- a atuação dos governos como formuladores de estratégias, políticas e planos de ação em saúde, articulada com a de outros setores e usando os recursos da saúde de forma racional;

- o direito e o dever dos povos de participar, individual e coletivamente, do planejamento e da execução dos cuidados em saúde;

- a cooperação entre países para assegurar saúde para todos os povos, uma vez que "a consecução da saúde do povo de qualquer país interessa e beneficia diretamente todos os outros países";

- a defesa de políticas de independência dos povos, de paz e de desarmamento, considerando-se que esta última poderia e liberaria recursos do campo bélico para a aceleração do desenvolvimento social e econômico dos países.

O documento produzido em Alma-Ata influenciou sobremaneira a atuação de alguns países, no que tange as suas formulações políticas de saúde, em função do entendimento a que se chegou na ocasião.

No Brasil, além dessa influência, havia, à época (final da década de 1970 e década de 1980), um movimento da sociedade por redemocratização e universalidade de acesso dos cidadãos aos direitos sociais e políticos. Esse mo-

${ }^{3} \mathrm{O}$ cuidado primário em saúde é o primeiro contato das pessoas com o sistema nacional de saúde, reflete as condições econômicas, políticas, culturais e sociais dos países, e têm em vista os principais problemas de saúde da comunidade e de outros setores (problemas na educação, nutrição inadequada, falta de água e saneamento). : Este cuidado primário em saúde requer e promove participação comunitária nas ações de saúde e depende de integração e funcionalidade dos vários profissionais, seus saberes e seus níveis de atuação em saúde (ALMA-ATA, 1978). 
mento histórico propiciou a consequente discussão sobre o futuro do sistema de saúde no país.

Em função da elaboração de uma nova Constituição, convocou-se, em 1986, a $8^{a}$ Conferência Nacional de Saúde, para discutir uma nova proposta de estruturação e política do setor da saúde a ser apresentada para a Assembleia Nacional Constituinte. Com a participação de mais de quatro mil pessoas (dentre elas, usuários do sistema de saúde, profissionais de saúde, políticos e integrantes de lideranças diversas), a Conferência teve como temas centrais a saúde como direito de cidadania, a reformulação do sistema nacional de saúde de acordo com princípios de universalidade, a redefinição dos papéis das esferas governamentais, a descentralização e a integração de setores e instituições e o financiamento e a participação da comunidade (BRASIL, 1987).

A Conferência refletiu uma discussão iniciada em níveis municipais e estaduais e teve como conquista principal a elaboração de um projeto de Reforma Sanitária, defendendo a criação de um sistema de saúde único e desvinculado da previdência, instituição centralizadora de políticas governamentais para o setor saúde, regionalizado em termos de gerenciamento da prestação de serviços universais e públicos (FIOCRUZ, 2008).

Conforme o Relatório Final da Conferência, a saúde ficou entendida como resultante de fatores como alimentação, habitação, educação, renda, meio ambiente, trabalho, transporte, emprego, lazer, liberdade de acesso à terra, posse da terra e acesso a serviços de saúde (BRASIL, 1987). Compreendendo a saúde por meio deste amplo conceito, princípios como universalidade, igualdade, intersetorialidade e racionalidade foram colocados em pauta.

$\mathrm{Na}$ elaboração da Constituição Cidadã, promulgada em 1988, incluiuse uma seção sobre saúde, com alguns conceitos e propostas debatidas na $8^{\mathrm{a}}$ Conferência, incorporando, desta for- ma, à Constituinte, propostas defendidas pelo Movimento da Reforma Sanitária. No texto constitucional, todos são iguais perante a lei e a saúde é tida como um direito social e universal. Definiu-se, ali, que o sistema de saúde a ser implantado no país integraria uma rede regionalizada e hierarquizada e constituiria um sistema único, organizado de acordo com as seguintes diretrizes: descentralização, com direção única em cada nível de governo; atendimento integral, com prioridade para as atividades preventivas, sem prejuízo dos serviços assistenciais; e participação da comunidade (BRASIL, 1988).

Com a LOS, os princípios norteadores do novo sistema de saúde do país foram detalhados, abrangendo, principalmente: universalidade de acesso, integralidade de assistência, igualdade da assistência, participação da comunidade, descentralização político-administrativa (direção única em cada esfera de governo, descentralização dos serviços para os municípios, regionalização e hierarquização da rede de serviços de saúde); integração das ações de saúde, meio ambiente e saneamento básico, e, ainda, resolutividade.

A partir dos seus princípios, o novo sistema de saúde do país foi regulamentado pela LOS, na qual se explicita a saúde como um direito fundamental do ser humano, cabendo ao Estado prover as condições para seu pleno exercício, por meio da formulação e execução de políticas econômicas e sociais, do estabelecimento de condições que assegurem acesso universal e igualitário às ações e aos serviços de saúde. Além disso, a LOS define formalmente os fatores determinantes e condicionantes da saúde, como alimentação, moradia, saneamento básico, dentre outros (BRASIL, 1990a):

Art. $3^{\circ}$. A saúde tem como fatores determinantes e condicionantes, entre outros, a alimentação, a moradia, o saneamento básico, o meio ambiente, o trabalho, a renda, a educação, 
o transporte, o lazer e o acesso aos bens e serviços essenciais; os níveis de saúde da população expressam a organização social e econômica do País.

Parágrafo único. Dizem respeito também à saúde as ações que, por força do disposto no artigo anterior, se destinam a garantir às pessoas e à coletividade condições de bem-estar físico, mental e social (BRASIL, 1990a).

O campo de atuação do sistema está, conforme a LOS (BRASIL, 1990a; 1990b), na execução de ações de vigilância sanitária, epidemiológicas, de saúde do trabalhador e de assistência terapêutica integral; na participação da sociedade na formulação da política e na execução de ações de saneamento básico; na ordenação da formação de recursos humanos na área de saúde; na vigilância e na orientação nutricional; na colaboração para a proteção do meio ambiente (inclusive o meio ambiente do trabalho); na formulação da política de medicamentos, equipamentos, imunobiológicos e outros insumos de interesse para a saúde; na participação na produção destes insumos; no controle e na fiscalização de serviços, produtos e substâncias de interesse para a saúde; na fiscalização e inspeção de alimentos, água e bebidas para consumo humano; na participação da sociedade no controle e na fiscalização da produção, do transporte, da guarda e da utilização de substâncias e produtos psicoativos, tóxicos e radioativos; no incremento do desenvolvimento científico e tecnológico na área da saúde; e na formulação e execução da política de sangue e seus derivados.

Implantado o SUS no país, propôs-se a passagem de um modelo de atenção à saúde medicalizado, hospitalocêntrico e curativo para um modelo voltado à prevenção e promoção da saúde, a partir do trabalho de equipes multidisciplinares e intersetoriais, com foco nas famílias e nas comunidades. Para a consolidação deste processo, adotouse a estratégia de promover a saúde da família (transitoriamente via PACS em 1991; depois PSF, em 1994; e finalmente via ESF, em 1998 e ratificação em 2011), que visa atender principalmente os princípios da universalidade de acesso e da integralidade da assistência à saúde, abarcando toda a rede de serviços básicos do sistema, através da ampliação e qualificação da atenção básica em saúde, da adoção de concepções como prevenção e promoção de saúde e da participação efetiva da comunidade, a partir de uma abordagem voltada à educação tanto de trabalhadores de saúde como de usuários do sistema, como forma de mudança e melhoria das condições de saúde e vida das comunidades e, consequentemente, do próprio país.

Pode-se verificar que a noção de sistema de saúde iniciado na época em questão é coerente com a proposição apresentada por Bertalanfy (1975), o qual coloca o sistema como um conjunto de partes relacionadas e organizadas sinergicamente, com vistas a realizar um propósito e como existente dentro de outros sistemas (subsistemas), interagindo com o meio em que se encontra, reagindo e ajustando-se dinamicamente. Outrossim, esta noção também está ancorada nas propriedades características de um sistema, que incluem, principalmente: adaptabilidade às condições do ambiente (ou de sustentabilidade), contínuo ajustamento aos requisitos internos, flexibilidade da estrutura compositiva, multidimensionalidade e multinivelabilidade, multidisciplinaridade, foco em objetivos e autocontrole (com capacidade de feedback), autonomia relativa das partes, subsidiariedade das partes (especialmente dos níveis mais amplos ou gerais em relação aos menores ou mais específicos), dentre outras (KLERING; SCHRÖEDER, 2011). Tendo em vista a definição de sistema, às propriedades referidas podem ser acrescentadas, também, as propriedades básicas da integração das partes; da si- 
nergia das partes; da integralidade (porque um sistema é formado pelo conjunto das partes, de modo que a alteração em uma parte afeta o todo, e vice-versa); da existência de fronteira entre cada parte e entre o sistema e seu ambiente; e da sinergia. Nesse sentido, pode-se identificar um paralelismo entre os princípios e as diretrizes do SUS e as propriedades de um sistema, conforme explicitado no Quadro 1:

\begin{tabular}{|c|c|}
\hline Princípios e diretrizes do SUS & Propriedades sistêmicas relacionadas \\
\hline $\begin{array}{l}\text { a) universalidade de acesso a partir do } \\
\text { trabalho de equipes multidisciplinares e de } \\
\text { intersetorialidade, com foco nas famílias e } \\
\text { nas comunidades; }\end{array}$ & $\begin{array}{l}\text { - integralidade; } \\
\text { - multidisciplinaridade; } \\
\text { - multidimensionalidade; }\end{array}$ \\
\hline b) integralidade de assistência; & - integralidade; \\
\hline c) participação da comunidade; & $\begin{array}{l}\text { - integração, autonomia relativa e sinergia } \\
\text { das partes; }\end{array}$ \\
\hline d) igualdade da assistência à saúde; & - sem propriedade paralela específica; \\
\hline $\begin{array}{l}\text { e) descentralização político-administrativa } \\
\text { (direção única em cada esfera de governo, } \\
\text { descentralização dos serviços para os mu- } \\
\text { nicípios, regionalização e hierarquização da } \\
\text { rede de serviços de saúde); }\end{array}$ & $\begin{array}{l}\text { - autonomia relativa das partes; } \\
\text { - multidimensionalidade e multinivelabili- } \\
\text { dade; }\end{array}$ \\
\hline $\begin{array}{l}\text { f) integração das ações de saúde, meio } \\
\text { ambiente e saneamento básico; }\end{array}$ & - integração das partes; \\
\hline g) resolutividade; & $\begin{array}{l}\text { - alcance dos objetivos; } \\
\text { - foco; }\end{array}$ \\
\hline $\begin{array}{l}\text { h) sem princípio e diretriz do SUS cor- } \\
\text { respondentes específicas, embora implici- } \\
\text { tamente alguns estejam presentes, como } \\
\text { o patamar mínimo a ser gasto em saúde, } \\
\text { conforme a Lei de Responsabilidade Fiscal } \\
\text { (LRF) }\end{array}$ & $\begin{array}{l}\text { - de adaptabilidade às condições do ambien- } \\
\text { te-sustentabilidade (tais como: definição do } \\
\text { número de ESF, localização etc.); }\end{array}$ \\
\hline $\begin{array}{l}\text { i) sem princípio e diretriz do SUS corres- } \\
\text { pondentes específicas, embora estejam } \\
\text { implicitamente presentes; }\end{array}$ & $\begin{array}{l}\text { - contínuo ajustamento aos requisitos } \\
\text { internos (tendo em vista reestruturações na } \\
\text { hierarquia, alterações do orçamento, outras } \\
\text { alterações em processos internos); }\end{array}$ \\
\hline $\begin{array}{l}\text { j) sem princípio e diretriz do SUS corres- } \\
\text { pondente específica, embora atendendo a } \\
\text { especificações mínimas, tal como a compo- } \\
\text { sição profissional das ESF }\end{array}$ & - flexibilidade da estrutura compositiva; \\
\hline $\begin{array}{l}\text { k) sem princípio e diretriz do SUS cor- } \\
\text { respondentes específicas, embora estejam } \\
\text { implicitamente presente; }\end{array}$ & $\begin{array}{l}\text { - autocontrole (com capacidade de fee- } \\
\text { dback); }\end{array}$ \\
\hline $\begin{array}{l}\text { 1) sem princípio e diretriz do SUS corres- } \\
\text { pondentes específicas, embora estejam } \\
\text { implicitamente presentes na sua definição } \\
\text { pela LOS. }\end{array}$ & - subsidiariedade das partes. \\
\hline
\end{tabular}

O Quadro 1 permite identificar algumas lacunas do SUS, as quais, se preenchidas, permitirão que este opere de forma mais plena como sistema. Dentre estas lacunas, podem ser apontadas limitações quanto à definições mais claras sobre as seguintes propriedades sistêmicas: adaptabilidade às condições do ambiente; 
contínuo ajustamento aos requisitos internos; flexibilidade da estrutura compositiva; e subsidiariedade das partes.

$O$ tópico a seguir destina-se a apresentar a ESF, criada como programa governamental, mas que assumiu contornos mais amplos e determinantes para a mudança na política nacional de saúde, bem como para outros setores.

\subsection{A Estratégia de Saúde da Família}

A Estratégia de Saúde da Família (ESF) formou-se a partir de dois programas ministeriais: o Programa de Agentes Comunitários de Saúde (PACS), precursor do Programa de Saúde da Família (PSF). O PSF foi oficializado pelo Ministério da Saúde, em março de 1994. Neste momento, o Ministério da Saúde institucionalizou experiências de práticas em saúde com agentes comunitários, as quais já vinham sendo desenvolvidas de forma isolada em diversas regiões do Brasil (ANDRADE, 2002).

Estas iniciativas ganharam destaque no Estado do Ceará, onde esta prática de saúde foi transformada em uma política estadual (ANDRADE, 2002). Em 1990, havia, no Ceará, alto índice de morbidade e mortalidade, especialmente infantil, devido a uma forte seca que assolou o Estado. Milhares de famílias foram acometidas pela fome proveniente da seca. Nesta situação de emergência, foi decidido mobilizar duzentas mil pessoas, das quais seis mil eram mulheres, para a área da saúde. Sem qualquer formação profissional, estas pessoas eram conhecidas e respeitadas por suas comunidades de origem, e a elas coube o trabalho de incentivo à vacinação de todas as crianças, ao acompanhamento pré-natal de gestantes e ao ensino do uso do soro oral contra a desidratação. Ao terminar o programa de emergência de atendimento à seca, somente as "mulheres da saúde" permaneceram trabalhando, devido ao sucesso de suas atividades (NOGUEIRA et al., 2000).

Assim, no início dos anos 1990, percebendo, através da experiência ocorrida no Estado do Ceará, que os agentes de saúde poderiam ser peça importante para a organização da atenção básica nos municípios (ANDRADE, 2002), o Ministério da Saúde decidiu estender esta experiência para o SUS como um todo, sendo sua implantação definida conforme o Mapa da Fome. Visando o atendimento integral da população, equipes multidisciplinares foram sendo formadas, incluindo-se nelas também os denominados "visitadores de saúde", que tinham conhecimento dos problemas de sua comunidade e os traziam à tona para que fossem analisados e, se possível, resolvidos. Objetivando atender à demanda deficitária da atenção primária, o Ministério da Saúde juntamente com a Fundação Nacional de Saúde criaram oficialmente o Programa de Agentes Comunitários de Saúde (PACS), em 1991. Em 1994, surgiram as primeiras equipes do PSF, as quais forneciam retaguarda assistencial ao trabalho do PACS (BONASSA; CAMPOS, 2001). A partir de 1995, houve um período marcado pela expansão da atenção básica em saúde, incentivada pelo Ministério da Saúde e pelas secretarias estaduais de saúde, ao mesmo tempo em que se avançava no processo de municipalização e no estabelecimento de novas sistemáticas para o financiamento das ações e serviços de saúde (MENDES; MARQUES, 2004). Esta expansão da atenção básica em saúde foi também uma forma de tentar racionalizar mais o sistema, através do acesso ao mesmo e de sua resolutividade.

Em 1997, o PACS e o PSF foram incluídos na agenda de prioridades da política nacional de saúde, e, em 1998, o PSF passou a ser considerado como estratégia estruturante da organização do SUS. Assim, pela primeira vez, houve a definição de um orçamento próprio para o PSF no Plano Plurianual (BRASIL, 2004a). Ocorreu, então, uma grande expansão no volume de Equipes de Saúde da Família em todo o país. Em 
2001, foi editada a Norma Operacional de Assistência à Saúde $n^{\circ}$ 01/2001, que redefiniu funções e responsabilidades de cada esfera de governo, estabelecendo que a gestão da atenção básica à saúde cabe a todos os municípios (BRASIL, 2001a). A partir de 2003, deu-se início ao Programa de Expansão e Consolidação da Estratégia de Saúde da Família (PROESF), reforçando, desta forma, a intenção de orientação do modelo de atenção à saúde através da ESF. No final de 2007, foi lançado o Programa Mais Saúde: direito de todos (concernente ao campo da saúde do Plano de Aceleração do Crescimento do Governo Federal), prevendo maior aporte de recursos para a saúde, com foco na atenção bási- ca como fundamental, na expansão das Equipes de Saúde da Família, e na criação de núcleos de apoio a estas Equipes (BRASIL, 2008a).

Em 2011, a portaria GM $n^{\circ}$ $2.488 / 2011$ revisou e atualizou as diretrizes e normas para a organização da atenção básica e aprovou a Política Nacional de Atenção Básica para a ESF e para o PACS.

Atualmente, a ESF alcança cerca de $58,9 \%$ da população brasileira, o que corresponde a aproximadamente 114,5 milhões de pessoas (BRASIL, 2012). A evolução da implantação das Equipes de Saúde da Família no Brasil e a quantidade de pessoas e famílias atendidas, de 1998 a 2011, podem ser visualizadas na Figura a seguir:

\begin{tabular}{lrr} 
Ano & No Pessoas & No Famílias \\
\hline 1998 & 23.896 .924 & 5.141 .520 \\
1999 & 38.839 .841 & 9.262 .705 \\
2000 & 62.929 .042 & 15.649 .257 \\
2001 & 76.748 .215 & 19.593 .720 \\
2002 & 86.099 .576 & 22.121 .720 \\
2003 & 93.033 .731 & 24.138 .664 \\
2004 & 97.646 .980 & 25.576 .286 \\
2005 & 102.958 .094 & 27.292 .193 \\
2006 & 108.836 .647 & 29.164 .933 \\
2007 & 109.934 .109 & 29.958 .783 \\
2008 & 112.761 .530 & 31.273 .499 \\
2009 & 115.936 .690 & 32.134 .850 \\
2010 & 123.732 .265 & 34.724 .377 \\
2011 & 114.587 .183 & 32.589 .020
\end{tabular}

Figura 1 - Evolução da implantação de Equipes de Saúde da Família: 1998 - 2011 Fonte: Adaptada de Brasil (2012).

Enquanto estratégia de reorganização das práticas tradicionais de trabalho e de reestruturação do modelo de atenção à saúde, a operacionalização das Equipes de Saúde da Família dá-se através das unidades básicas de saúde, em caráter substitutivo e hierarquizado. O Ministério da Saúde trabalha com territorialização e adscrição de população, cuja prática deve comprometer-se com a programação e o planejamento descentralizados; a integralidade da assistência; a abordagem multiprofissional; o estímulo à ação intersetorial; o estímulo à participação e ao controle social; a adoção permanente dos profissionais das equipes e a adoção de instrumentos permanentes de acompanhamento e avaliação (BRASIL, 1997b).

Em outras palavras:

Neste espaço da prática de Saúde da Família, assume-se alguns compromissos importantes: estender a família, o seu espaço social como núcleo básico da abordagem e não mais o 
indivíduo isoladamente; assistência integral, resolutiva, contínua e de boa qualidade; intervenção sobre os fatores de risco; humanização das práticas de saúde; criação de vínculos de compromisso e de co-responsabilidade entre os profissionais de saúde e a comunidade; desenvolvimento de ações intersetoriais através de parcerias; democratização do conhecimento do processo saúde, doença, da organização do serviço e da produção social da saúde; reconhecimento da saúde como um direito de cidadania e organização da comunidade para efetivo exercício do controle social (SOUZA, 2002, p. 24-25).

Cabe ressaltar que as Equipes de Saúde da Família desenvolvem ações de promoção da saúde, de prevenção de doenças e agravos, de diagnóstico precoce, de tratamento e de reabilitação, tendo como campos de estudo o diagnóstico de doenças, a intervenção, o indivíduo, a família, o ambulatório, a comunidade e o meio ambiente.

Partindo desta estratégia de atenção à saúde, surge a figura do agente comunitário de saúde, um profissional considerado híbrido, pois, além de ser membro da Equipe de Saúde, mora na comunidade em que atua, vivenciando sua realidade. Dessa forma, percebe-se que o agente está na base do novo modelo de atenção à saúde, uma vez que é ele quem adentra nas casas e conhece as pessoas de cada família da comunidade em que trabalha. $\mathrm{O}$ agente é o profissional de saúde a quem compete o acesso primário ao sistema de saúde, bem como a função de olhar para o todo da comunidade e motivar as pessoas ao cuidado coletivo em saúde e à participação social nesta área. Ele recebe e repassa ensinamentos capazes de mostrar, na prática, como se prevenir contra as doenças (BRASIL, 1997a).

A atuação do agente comunitário de saúde é considerada estratégica por ser uma forma inteligente de atuação, mais efetiva do que outras formas ou caminhos isolados de ação, visando alcançar um futuro almejado por uma comunidade (KLERING; SCHRÖEDER, 2008), ou seja, uma situação melhor de saúde e de bem-estar das pessoas de determinada comunidade. Outrossim, como estratégia, seu enfoque é mais amplo do que o de um programa, de um plano ou de uma ação, englobando vários níveis ao mesmo tempo.

Prestando cuidados primários às famílias da sua própria comunidade, o agente auxilia as pessoas a cuidarem da própria saúde através de ações individuais e coletivas, nunca trabalhando de forma isolada, uma vez que seu trabalho envolve a participação de diversos atores em diferentes níveis de relacionamento e de atividades. O resultado do trabalho do agente depende da equipe de saúde local, das secretarias de saúde, das diversas instituições da sociedade civil e, principalmente, das famílias inseridas na comunidade. Este profissional pode atuar, também, em parceria com órgãos públicos e com instituições, como Pastorais da Criança, Pastorais da Saúde, Clubes de Mães, Associações de Moradores, sempre em conformidade com as prioridades de sua comunidade (BRASIL, 1997a). Para desenvolver seu trabalho, o agente precisa de informações básicas sobre todos os assuntos que interessam à saúde da comunidade em que ele atua e vive, pois, ao reunir tais informações, ele pode fazer um diagnóstico (BRASIL, 1997a), identificando os problemas, as necessidades e os recursos de uma comunidade, passo importante para o processo de planejamento em saúde comunitária. Em outras palavras, é o agente comunitário que atua mais próximo às comunidades, e é através de seu trabalho que este profissional se torna um elo entre a sua comunidade e os serviços e profissionais de saúde (TUNES et al., 1995).

\section{A abordagem das capacitações}

Vivemos em um mundo de opulência 
sem precedentes... tem havido mudanças notáveis para além da esfera econômica... regime democrático e participativo como o modelo preeminente de organização política... direitos humanos e liberdade política são (...) parte da retórica prevalecente. As pessoas vivem (...) mais tempo (...) as diferentes regiões do globo estão agora mais estreitamente ligadas (...). Entretanto, vivemos igualmente em um mundo de privação, destituição e opressão extraordinárias. Existem problemas novos convivendo com os antigos - a persistência da pobreza e de necessidades essenciais não satisfeitas, fomes coletivas e fomes crônicas (...), violação de liberdades (...), negligências e ameaças (...) (SEN, 2000).

Sen (2000) defende que a parte central do processo de desenvolvimento de uma sociedade é superar problemas como a persistência da pobreza, o não atendimento às necessidades essenciais, as fomes coletivas e crônicas, a violação de liberdades, a negligência em relação às mulheres e as ameaças ao meio ambiente. $\mathrm{O}$ autor também aponta que há uma lacuna entre a riqueza e as condições de vida, duas perspectivas que devem ser consideradas ao se abordar um conceito ou uma concepção de desenvolvimento. Para ele, o desenvolvimento deve ir além da riqueza e de sua utilidade, a qual está nas coisas que as pessoas podem fazer por si mesmas e pelo estilo de vida que almejam para si. É preciso, pois, relacionar o desenvolvimento com a melhora da vida que se leva e das liberdades que são desfrutadas pelas pessoas.

Para o autor, desenvolvimento é, então, entendido como algo constituído pela eliminação de privações de liberdades substanciais, as quais limitam escolhas e oportunidades das pessoas em exercer sua condição de agente, ou, ainda, como um processo de expansão das liberdades reais de que as pessoas desfrutam. Seja devido a sua expansão, seja devido à eliminação das privações, a liberdade das pessoas é o principal objetivo do desenvolvimento e seu ponto de vista é a perspectiva norteadora dele. A liberdade das pessoas é o que o desenvolvimento promove, é o meio principal e o fim primordial do desenvolvimento, e sua ausência pode mostrar-se de várias formas. Por exemplo, a ausência pode ser relativa à pobreza econômica, situação na qual as pessoas não são livres para satisfazer suas necessidades básicas, como alimentação, saneamento e moradia, assim como pode ser relativa à falta de serviços públicos e de assistência social, ou, ainda, relativa à negação de participar da vida política da sociedade em que vivem.

Para Sen (2000), o desenvolvimento constitui um processo integrado de expansão de liberdades substantivas interligadas, considerando-se aspectos econômicos, sociais e políticos.

Nesse contexto, os meios (as condições de vida) devem ser entendidos como instrumentos do desenvolvimento, enquanto os fins (as liberdades reais para o alcance de realizações) devem ser vistos como os principais objetivos do desenvolvimento.

A Abordagem das Capacitações, de Amartya Sen $(1985,2000)$, desloca o foco da atenção do desenvolvimento dos meios (as condições de vida) para os fins de vida das pessoas, ou seja, as liberdades para o alcance de realizações. Constitui um método (framework) teórico que destaca a necessidade de uma mudança de foco na informação necessária para a realização de julgamentos sobre bem-estar, concedendo importância derivativa aos meios de vida e considerando o que realmente importa, focando, assim, nos funcionamentos valiosos ("seres e fazeres") que podem ser atingidos pelas pessoas (COMIM, 2001; COMIM; QIZILBASH; ALKIRE, 2008; FLORES-CRESPO, 2001). De acordo com a apresentação sintética da Stanford Encyclopedia of Philosophia (2011), a Abordagem das Capacitações destaca duas reivindica- 
ções normativas principais: a) a reivindicação de que a liberdade para alcançar o bem-estar é de importância moral primária e b) a reivindicação de que a liberdade, para o alcance do bem-estar, deve ser entendida em termos das capacidades pessoais, isto é, das suas reais oportunidades para ter e ser o que precisa ser valorizado. A Abordagem tem sido desenvolvida através de uma variedade de teorias normativas mais específicas, tais como a teoria da justiça social ou a teoria da ética do desenvolvimento. Esta abordagem também tem sido enfocada por uma perspectiva interdisciplinar nas ciências sociais, resultando em novas estatísticas e novos indicadores sociais, bem como em novos paradigmas políticos, que são usados principalmente em estudos sobre desenvolvimento, mais especificamente nas chamadas abordagens de desenvolvimento humano. Os textos de Comim, Qizilbash e Alkire (2008), Deneulin (2009) e Kuklys (2005) são boas fontes para um aprofundamento sobre a Abordagem das Capacitações pela perspectiva das ciências sociais. Para uma breve visão global sobre como a abordagem tem sido aplicada na prática, podem ser consultados os textos de Fukuda-Parr (2003) e Fukuda-Parr e Kumar (2009).

A Abordagem das Capacitações, proposta por Sen $(1985,2000)$, embasa-se em alguns conceitos essenciais, como: funcionamentos, capacidades, bem-estar, capacidade de agência e liberdades das pessoas.

\subsection{Funcionamentos e capacidades humanas}

Os funcionamentos humanos são as realizações do indivíduo, as várias coisas que ele realiza (ou pode realizar) e considera valioso ser, ter ou fazer. São diretamente relacionados às condições de vida do indivíduo, visto que refletem aspectos dos estados de existência e das condições de vida, os quais englobam: alimentação, habitação, saúde, educação, segurança, água potável, sa- neamento, bem como possibilidades de participação em associações, partidos, movimentos e na vida comunitária. Os funcionamentos humanos podem ser simples ou complexos.

As capacitações humanas representam, por sua vez, a liberdade (pela sua habilidade, aptidão) de o indivíduo alcançar combinações de funcionamentos, ou seja, combinações de estilos de vida possíveis ou do estilo de vida que este valoriza. Assim sendo, ao passo que os funcionamentos são pertinentes a coisas realizáveis (condições de vida alcançáveis), as capacitações são habilidades ou aptidões que o indivíduo possui para o alcance dessas coisas, através das liberdades e oportunidades que possui para escolher entre diferentes opções (SEN, 2000; PORSSE, 2006).

Assim, para fins de avaliações normativas, tais como aquelas envolvidas nas mensurações de bem-estar, a perspectiva da capacitação utiliza, como base informacional, as capacitações ou habilidades-aptidões dos indivíduos, ou seja, as combinações alternativas de funcionamentos que uma pessoa pode alcançar ou que são factíveis de alcance (SEN, 2000, 2005). O bem-estar é definido conforme algumas capacitações básicas que são requeridas para satisfazer certos funcionamentos relevantes para um indivíduo, tais como ser adequadamente nutrido, levar uma vida longa, saudável e criativa, ser alfabetizado, ter acesso ao conhecimento e à comunicação, desfrutar de um padrão de vida decente, ter liberdades, dignidade e autorrespeito. Desse modo, bem-estar, além de abranger múltiplos aspectos quantitativos e qualitativos, como renda, acesso a bens, educação, saúde, gênero, origem étnica, circunstâncias familiares, localização geográfica, dentre outros, depende destes (RELATÓRIO..., 1997).

Empregando a noção da capacitação humana como um fundamento para a elaboração de princípios políticos básicos, os quais devem ser considerados na elaboração de princípios constitucio- 
nais, Nussbaum (2000, p. 5) estabelece uma "lista de princípios constitucionais básicos que devem ser respeitados e implementados pelos governos de todas as nações, como um mínimo essencial que respeita os requerimentos da dignidade humana" (vide Quadro 2).

\begin{tabular}{|c|c|}
\hline Itens & Capacitação humana central \\
\hline 1. Vida & $\begin{array}{l}\text { Estar apto a viver até o final de uma vida humana de extensão normal; não morrer } \\
\text { prematuramente ou antes que a vida seja reduzida a uma vida considerada sem } \\
\text { valor. }\end{array}$ \\
\hline $\begin{array}{l}\text { 2. Saúde } \\
\text { do corpo }\end{array}$ & $\begin{array}{l}\text { Estar apto a ter boa saúde, incluindo saúde reprodutiva; estar adequadamente nutri- } \\
\text { do; ter abrigo adequado. }\end{array}$ \\
\hline $\begin{array}{l}\text { 3. Integridade } \\
\text { do corpo }\end{array}$ & $\begin{array}{l}\text { Estar apto a mover-se livremente de um lugar a outro; ter limitações do corpo tra- } \\
\text { tadas como soberanas, isto é, estar seguro contra agressões, incluindo agressão se- } \\
\text { xual, abuso sexual na idade infantil e violência doméstica; ter oportunidades para } \\
\text { satisfação sexual e para fazer escolhas quanto as questões reprodutivas. }\end{array}$ \\
\hline $\begin{array}{l}\text { 4. Sentido, } \\
\text { imaginação, e } \\
\text { pensamento }\end{array}$ & $\begin{array}{l}\text { Estar apto a usar os sentidos, a imaginar, pensar e raciocinar, executando estas ações } \\
\text { por um caminho verdadeiramente humano, um caminho informado e cultivado por } \\
\text { uma adequada educação (inclusive, mas não por meios limitados para), alfabetiza- } \\
\text { ção, matemática básica e por um adequado treinamento científico. Estar apto para } \\
\text { usar a imaginação e o pensamento em conexão com o ato de experimentar e produ- } \\
\text { zir trabalhos autoexpressivos e com eventos de escolha própria, de caráter religioso, } \\
\text { de alfabetização, musical, entre outros. Estar apto a usar a própria mente em cami- } \\
\text { nhos protegidos por garantias de liberdade de expressão com respeito a discursos } \\
\text { de natureza política ou artística e à liberdade do exercício religioso. Estar apto a } \\
\text { buscar o significado da vida em um caminho próprio. Estar apto a ter experiências } \\
\text { aprazíveis, para evitar sofrimentos desnecessários. }\end{array}$ \\
\hline 5. Emoções & $\begin{array}{l}\text { Estar apto a ter apego a coisas e pessoas fora de si mesmo; a amar aqueles que o } \\
\text { amam e preocupam-se consigo; para nos preocuparmos com eles na sua ausência; } \\
\text { em geral, para amar, para se preocupar, para experimentar desejo, gratidão e raiva } \\
\text { justificada. Não ter desenvolvimento emocional frustrado em função de medo da } \\
\text { opressão e de ansiedade, ou em função de eventos traumáticos, de abuso ou negli- } \\
\text { gência. (Sustentar esta capacitação significa sustentar formas de associação humana } \\
\text { que podem ser cruciais no seu desenvolvimento.) }\end{array}$ \\
\hline $\begin{array}{l}\text { 6. Raciocínio } \\
\text { prático }\end{array}$ & $\begin{array}{l}\text { Estar apto a formar uma concepção de bem e para se engajar na reflexão crítica } \\
\text { sobre o planejamento da própria vida, o que requer proteção para a liberdade de } \\
\text { consciência. }\end{array}$ \\
\hline 7. Afiliação & $\begin{array}{l}\text { A. Estar apto a viver com e em direção a outros, a reconhecer e mostrar preocupa- } \\
\text { ção pelos outros seres humanos, a poder engajar-se em várias formas de interação } \\
\text { social; a imaginar determinada situação a partir da perspectiva de outro, e a ter } \\
\text { compaixão pelo outro naquela situação. Ter a habilidade para agir com justiça e } \\
\text { amizade, uma vez que proteger esta capacitação significa proteger instituições que } \\
\text { constituem e nutrem tais formas de afiliação e protegem a liberdade de reunião e } \\
\text { discurso político. } \\
\text { B. Ter as bases sociais de autorrespeito e não humilhação; estar apto a ser tratado } \\
\text { como um ser digno cujo valor é igual ao dos outros. Isto requer, no mínimo, prote- } \\
\text { ções contra discriminação em relação a de raça, sexo, orientação sexual, religião, } \\
\text { castidade, etnicidade, ou origem nacional. No trabalho, estar apto a trabalhar como } \\
\text { um ser humano, exercendo raciocínio prático e entrando em significativas relações } \\
\text { de reconhecimento mútuo com outros trabalhadores. }\end{array}$ \\
\hline $\begin{array}{l}\text { 8. Outras } \\
\text { espécies }\end{array}$ & $\begin{array}{l}\text { Estar apto a viver com preocupação para e em relação aos animais, às plantas e a } \\
\text { outros elementos da natureza. }\end{array}$ \\
\hline 9. Interação & Estar apto a rir, a brincar e a desfrutar de atividades recreacionais \\
\hline $\begin{array}{l}\text { 10. Controle } \\
\text { sobre o próprio } \\
\text { ambiente }\end{array}$ & $\begin{array}{l}\text { A. Político: Estar apto a participar eficazmente das escolhas políticas que governam } \\
\text { a própria vida; ter o direito de participação política, ter proteções para discurso e } \\
\text { associações livres. } \\
\text { B. Material: Estar apto a possuir propriedade (terra e bens móveis), não somente } \\
\text { de maneira formal (contratual), mas em termos de oportunidades reais; ter direi- } \\
\text { tos de propriedade da mesma forma que outros; ter o direito para buscar emprego } \\
\text { igualmente aos outros; possuir proteção da liberdade de busca não autorizada e da } \\
\text { apreensão não justificada. }\end{array}$ \\
\hline
\end{tabular}

Quadro 2 - Lista de Nussbaum - capacitações funcionais humanas centrais

Fonte: Adaptado de Nussbaum (2000, p. 78-80). 
A lista de capacitações de Nussbaum (2000) tem por finalidade mostrar que as capacitações humanas podem constituir garantias de oportunidades para funcionarem, promovendo, de fato, a qualidade de vida dos seres humanos. Dessa forma, as capacitações humanas centrais não pretendem restringir-se apenas aos funcionamentos atuais, mas garantir e/ou proteger a possibilidade de acesso das pessoas a outros funcionamentos que sejam valorizados e que tenham razão para o serem. A função primordial das capacitações humanas centrais é a de promover a possibilidade de escolha de um caminho de vida possível. Assim, tais capacitações constituem um suporte para propósitos políticos em sociedades pluralistas. Seguindo essa perspectiva, o desenvolvimento é visto como um processo de ampliação das capacitações das pessoas, ou seja, das suas habilidades para fazer as coisas que elas valorizam e têm razão para valorizar e escolher.

\subsection{Capacidade de agência}

A condição de agente livre e sustentável, para Sen $(1985,2000)$, emerge como força motriz para o desenvolvimento, não apenas como parte constitutiva deste, mas também como contribuição para o fortalecimento de outros tipos de condições de agentes livres.

Todavia, o autor sabiamente lembra que (SEN, 2000, p. 19):

A ligação entre liberdade individual e realização de desenvolvimento social vai muito além da relação constitutiva - por mais importante que ela seja. O que as pessoas conseguem positivamente realizar é influenciado por oportunidades econômicas, liberdades políticas, poderes sociais e por condições habilitadoras, como boa saúde, educação básica e incentivo e aperfeiçoamento de iniciativas. As disposições institucionais que proporcionam essas oportunidades são ainda influenciadas pelo exercício das liberdades das pessoas, mediante a liberdade para participar da escolha social e da tomada de decisões públicas que impelem o progresso dessas oportunidades.

Assim sendo, neste estudo, considera-se um agente alguém que age de acordo com seus valores e objetivos próprios, interage e envolve-se em atividades individuais ou conjuntas em várias esferas e gera mudanças.

\subsection{As Liberdades humanas}

Sen (2000) apresenta uma distinção entre liberdades individuais, substantivas e instrumentais. As liberdades individuais são produtos sociais, influenciadas pelas concepções individuais de correção e de justiça, pela garantia social de liberdades, pela tolerância, pelas possibilidades de trocas e transações econômicas e pelo apoio público no fornecimento de serviços básicos de atenção à saúde e educação, por exemplo. Há uma via de mão dupla entre as disposições sociais que visam a expansão das liberdades individuais e o uso destas para melhorar a vida de cada pessoa e para tornar as disposições sociais mais apropriadas e eficazes.

As liberdades substantivas são parte de um processo de expansão de liberdades humanas e são relativas ao papel constitutivo que exercem no desenvolvimento humano. Elas incluem capacidades elementares e associadas, como ter condições de evitar fome, prevenir doenças e morte prematura, bem como de saber ler e calcular.

Por sua vez, a liberdade instrumental subdivide-se em outros cinco tipos de liberdades, conforme Sen (2000), que podem fortalecer-se e complementar-se mutuamente e que ajudam a promover a capacidade geral de uma pessoa, ou, ainda, contribuem, direta ou indiretamente, para o aumento da liberdade humana em geral, de forma que cada pessoa viva como gostaria de viver. 
As cinco liberdades são: a) liberdades políticas, que incluem os direitos civis e políticos e referem-se às oportunidades que as pessoas têm de determinar seus governantes, os princípios de governo e de fiscalização e crítica às autoridades; b) facilidades econômicas, que são oportunidades que as pessoas possuem de utilizar recursos econômicos com fins de consumo, troca ou produção; c) oportunidades sociais, que são as disposições que a sociedade estabelece, como ações e serviços de saúde e educação, e que influenciam a liberdade substantiva das pessoas para o alcance de uma vida melhor, além de serem importantes para a condução da vida privada, auxiliarem a efetividade da participação em atividades econômicas e políticas, bem como gerarem maior cooperação entre as pessoas; d) garantias de transparência, que se referem à necessidade das pessoas de poderem contar com aspectos como confiança, sinceridade, clareza e sem segredos do poder público e que desempenham papel importante no impedimento da corrupção, das ações ilícitas e da irresponsabilidade financeira; e, por fim, e) segurança protetora, que inclui disposições constitucionais fixas e medidas posteriores, como benefícios regulares aos desempregados e distribuição emergencial de recursos e que é necessária para impedir que a população vivencie situações de miséria, fome e morte (SEN, 2000).

Enfim, como apontado por Porsse (2006), a abordagem das capacitações não se caracteriza pelo princípio da eficiência, mas pelo da justiça. Amartya Sen (2011) reafirma esta concepção em sua recente obra, intitulada, na versão em português, "A idéia de justiça", na qual enfatiza a concepção de justiça algo que diz respeito "à vida que as pessoas são realmente capazes de levar", ou "à justiça realizada", em contraposição à corrente hegemônica ocidental do "institucionalismo transcendental" (ou da justiça como adequação organizacional), que se concentra nas utopias conceituais de uma justiça perfeita. A partir do trabalho pioneiro sobre justiça como equidade, de John Rawls (1997), Sen (2011) baseia sua teoria da justiça na noção de equidade, reconhecendo que as pessoas, embora sejam iguais perante a lei, possuem necessidades, capacidades e desejos distintos, implicando que a promoção da equidade na justiça constitua o caminho político a ser seguido para a diminuição das desigualdades sociais e econômicas do mundo contemporâneo, bem como para a universalização das liberdades democráticas.

\section{Reflexões...}

4.1 Prática discursiva na Estratégia de Saúde da Família: antes, e acima de tudo, educação!

A reflexão a seguir parte das práticas discursivas em torno da Estratégia de Saúde da Família (ESF). Entende-se, neste estudo, prática discursiva de uma forma ampliada, que abarca muito mais do que a fala de atores. Assim sendo, ela é fala e ação, é algo que pode ser verbal ou não, oral ou não. Fairclough (2005) compreende o discurso como sendo representação e significação do mundo, como um reflexo de uma realidade social mais profunda (que o molda e o restringe), que contribui para a formação das identidades sociais e das posições dos sujeitos para construir as relações sociais e os sistemas de conhecimento e crença, correspondendo, pois, às funções da linguagem e às dimensões de sentido que coexistem e interagem em todos os discursos, a saber: identitária, relacional e ideacional. Desse modo, a prática discursiva contribui para reproduzir e para transformar a sociedade.

O processo de reflexão deste estudo teve como ponto de partida textos produzidos no campo da saúde, embora não objetive utilizar, sistemática e metodologicamente, uma abordagem específica de análise de discurso. A análise 
de textos é um recurso seletivo e suplementar que ajuda na compreensão de processos sociais (MISOCZKY, 2005).

Alguns documentos foram de suma importância para este processo de reflexão, dentre eles: o relatório da $1^{\text {a }}$ Mostra Nacional de Vivências Inovadoras de Gestão do Sistema Único de Saúde (SUS) (BRASIL, 2006); algumas edições da Revista Brasileira de Saúde da Família; os relatórios das Mostras de Produção em Saúde da Família e as descrições normativas de políticas e programas em saúde relacionados à atuação em atenção básica e, consequentemente, à Saúde da Família.

A $1^{\text {a }}$ Mostra Nacional de Vivências Inovadoras de Gestão do SUS, organizada com o objetivo de divulgar, compartilhar e premiar as experiências de práticas inovadoras e transformadoras da saúde no SUS, sob os eixos temáticos de Organização da Atenção Integral em Saúde, Gestão do Cuidado em Saúde e Condução do Sistema de Saúde, contou com a participação de mais de 3.500 pessoas. Foram apresentados 916 trabalhos, a maioria deles referentes a ações desenvolvidas no esteio da ESF, a partir das quais foram descritas implantações de serviços agregação de categorias profissionais nas equipes e apresentações dos resultados de tais ações, o volume de procedimentos realizados e os reflexos em termos de índices de morbi-mortalidade. Cabe pontuar que a maioria destes trabalhos, mesmo aqueles que descrevem a implementação de programas e serviços, referem-se a ações de educação para e nas famílias e comunidades, com apresentações em termos epidemiológicos e também em termos qualitativos sobre a melhoria das condições de vida nas comunidades em que tais ações são desenvolvidas (BRASIL, 2006). O mesmo perfil é observado nos relatos das Mostras Nacionais de Produção em Saúde da Família (BRASIL, 2004c; 2008a; 2008b). Já foram realizadas três mostras nacionais, cujos relatórios apontam ações de saúde, bem como articulações do setor de saúde com outros setores e outras áreas de atuação: educação, saneamento, meio ambiente, artes e cultura, refletindo práticas similares. A segunda mostra, por exemplo, teve 1620 trabalhos apresentados, cujas ênfases recaíram sobre os processos de trabalho, monitoramento e avaliação das equipes, na educação continuada, popular e permanente (BRASIL, 2004c). Percebe-se, assim, que, geralmente, não aparecem, em tais relatórios, ações em saúde da família que sejam desvinculadas do fazer educativo

Nesse sentido, em relação a políticas nacionais de saúde, o Programa Mais Saúde: direito para todos apresenta o Programa Saúde na Escola (PSE) como política de articulação e de integração entre as ações desenvolvidas nas escolas e nas unidades básicas de saúde, especialmente nas de saúde da família. Entende-se, neste programa, a escola como espaço privilegiado para práticas de promoção e prevenção da saúde (BRASIL, 2008a). Humberto Costa (2005, p. 6), enquanto ministro da saúde, afirma, em uma carta aos educadores, que:

Saúde é qualidade de vida e, portanto, encontra-se vinculada aos direitos humanos, ao direito ao trabalho, à moradia, à educação, à alimentação e ao lazer. A escola é um espaço onde se constituem os cidadãos desses direitos, por meio de práticas realizadas por sujeitos sociais críticos e criativos, capazes de construir conhecimentos, relações e ações que fortalecem a participação das pessoas na busca de vidas mais saudáveis.

Políticas, programas e campanhas nacionais no setor da saúde são vários e reiterados: eliminação da hanseníase, controle da tuberculose, incentivo ao aleitamento materno e ao parto normal, combate ao tabagismo, controle de hipertensão e diabetes, prevenção de DST/AIDS, humanização, 
imunizações, prevenção da violência doméstica, infantil e no trânsito, redução de danos, etc. Todas essas ações são dependentes da atuação das equipes de SF e conformadas para a orientação do cidadão a fim de que ele tome as rédeas de seu próprio cuidado, por meio do conhecimento.

Os relatos das ações das equipes de SF defendem a importância de educar os cidadãos para que saibam participar das reflexões, dos debates e das deliberações pertinentes à sociedade, principalmente no campo da saúde coletiva. Nos mesmos, aparecem como recorrentes os temas: educação e saúde, educação em saúde e educação para a saúde.

É indiscutível que os níveis de educação - entendendo-se educação no seu caráter formal e a partir dos conhecimentos que são repassados, adquiridos e construídos - influenciam os resultados em saúde de uma população. No caso do Brasil, é possível afirmar que os índices relativos à qualidade de vida da população brasileira, que são direta ou indiretamente resultantes da atuação na área da saúde, em sua maioria, têm apresentado melhorias contínuas, como: aumento da expectativa de vida, redução da mortalidade infantil e materna, redução de mortalidade por causas evitáveis, ampliação de acesso a serviços de saneamento, à água tratada e ao recolhimento/tratamento de resíduos.

A educação tornou-se, portanto, a palavra-chave do SUS, principalmente na atuação em atenção básica/ESF, marcada pelo enfoque e de promoção da saúde e de prevenção. Aliar os dois campos (saúde e educação) parece fortalecer a saúde não como resultado ou produto de ações, mas como estratégia com grande potencialidade para articular e mobilizar outros setores, uma vez que pode gerar processos de reflexão e discussão (notável característica historicamente construída neste setor), que levam os cidadãos a buscar melhorias na qualidade de vida, para além da mera ausência de doença.
Um desafio da ESF diz respeito à expansão, à formação e à qualificação de seus trabalhadores, posto que, para a ESF, todos os profissionais de saúde da família deveriam ter formação voltada à saúde coletiva e à multidisciplinaridade, visto que serão, necessariamente, educadores em sua atuação. Além disso, na busca pela qualidade da atenção à saúde, todo e qualquer profissional de saúde, especialmente aquele em formação, deve ter profundo conhecimento do que é o sistema de saúde brasileiro e de suas peculiaridades.

No campo da saúde, adota-se, então, um discurso menos vinculado à educação continuada e mais vinculado à educação permanente em saúde (EPS)4 e à educação popular, principalmente sob a ótica de uma educação que seja significativa, que faça sentido e que se paute pelas realidades de quem a apreende. A intenção deste discurso é modificar as representações do processo saúde-doença, tanto dos trabalhadores como dos demais cidadãos. Dessa forma, a adoção de uma prática pedagógica passa a ser essencial para formar e qualificar trabalhadores de saúde para que compreendam o sistema de saúde e sua proposta de atuação, principalmente, quanto à atenção básica e à ESF e que se comprometam com este sistema, agindo como multiplicadores da formação e qualificação dos cidadãos.

Assim, estes últimos, dotados de conhecimento e de capacidade de participação nas e articulação das decisões políticas em saúde e nos setores relacionados, poderão buscar, por si sós, qualidade de vida. Em outras palavras, educar, sob diversos conceitos e formatos, revela-se importante para formar cidadãos que saibam do que precisam para

\footnotetext{
${ }^{4}$ Há diferenças conceituais entre educação continuada e educação permanente. A primeira englobaria atividades de ensino após o término do curso de graduação, com fins de atualização (RICAS, 1994 apud RIBEIRO; MOTTA, 2008), de manutenção ou de melhoria de competências individuais para $o$ desenvolvimento de suas responsabilidades, envolvendo conhecimentos e habilidades (DAVINI, 1994 apud RIBEIRO; MOTTA, 2008). Por outro lado, a concepção de educação permanente em saúde (EPS) foca o processo de trabalho como objeto de transformação e como centro privilegiado de aprendizagem, orientado para a melhoria da qualidade dos serviços e para a equidade no acesso e no cuidado, a partir de uma estética pedagógica de problematização e de intervenção (CECCIM, 2005).
} 
a melhoria de suas condições de vida e das de suas comunidades, conheçam seus direitos e as formas de obtê-los e exerçam efetivo controle social.

5 Considerações finais - capacitações, saúde da família e educação em saúde

A Abordagem das Capacitações, ao focar mais a qualidade de vida das pessoas e as liberdades substantivas, do que a utilidade, a renda e a riqueza destas, afasta-se das teorias tradicionalmente predominantes na economia. $\mathrm{O}$ mesmo ocorre com o Sistema Único de Saúde (SUS) e com a Estratégia de Saúde da Família (ESF), os quais surgiram na contramão do discurso dominante dos ajustes estruturais da década de 1990 e das práticas tradicionais de atenção. Em relação ao SUS como um todo, é preciso considerar que o país enfrenta, desde a concepção do novo sistema de saúde, a crítica da constituição social democrata, do discurso de reforma do aparelho do Estado e, consequentemente, da reforma administrativa da saúde - a qual teria um cunho social-liberal (PEREIRA, 2002) -, das pressões das agências internacionais e das tendências das leis de mercado, e tenta caminhar para a construção de um estado mínimo, o qual teria responsabilidade sobre um conjunto de ofertas à população e atenderia a população carente, compromisso que difere do qual se assumiu inicialmente. Há uma visão difundida de que o SUS não é financiável e não dispõe de recursos orçamentários para garantir o princípio constitucional de universalidade. Além disso, existe um dilema entre a perspectiva de contenção e de racionalização dos gastos e a busca de equidade e de justiça social por parte do SUS (PEREIRA, 2002; SENNA, 2002; CALLAHAN, 2002).

A forma de organização do sistema de saúde através da ESF é de atuação substitutiva de enfoques como medicalização, hospitalocentrismo e tratamento de doenças, pois tem, como núcleo básico da abordagem, o objetivo de compreender o indivíduo não por si só, mas em sua relação com a família e com o espaço social em que está inserido, de forma a dar assistência integral, resolutiva, contínua e de boa qualidade; a intervir em fatores de risco; a humanizar as práticas de saúde; a criar vínculos de compromisso e de corresponsabilidade entre comunidades e profissionais de saúde; a desenvolver ações intersetoriais através de parcerias; a democratizar o processo saúde-doença e de forma a reconhecer a saúde como um direito de cidadania e de organização da comunidade para o exercício de controle social (SOUZA, 2002).

Considerando-se um contexto de disputas de atores nos governos e na sociedade, marcado, não apenas pelas lutas por poder, mas também por vaidades, pode-se afirmar que as propostas citadas são ousadas, porque contradizem posições anunciadas, especialmente as da esfera político-partidária, ao focar não aspectos relativos à eficiência, mas sim relativos à qualidade de vida das populações e resultados de médio -longo prazo Além disso, agir para preparar, habilitar ou capacitar as pessoas, as famílias e as comunidades para que busquem aquilo que precisam ou desejam para viverem da forma como valorizam ou creem que seja digno viver é uma forma de descentralizar o poder de decisão das mãos de alguns, passando-o para a mão de muitos.

Enfim, pensar em capacitações e em educação para a saúde com a intenção de mudança e transformação social requer uma visão bastante ampla em relação ao tempo e aos espaços para a concretização desta intenção.

A ESF não foi pensada e não vem sendo orientada pela abordagem das capacitações, ao menos, não expressamente. Todavia, os caminhos desta e da Abordagem das Capacitações parecem convergir cada vez mais para um mesmo ponto. Por exemplo, a proximidade entre a propriedade de aplicação 
da noção de equidade na saúde e a de aplicação na justiça em geral (visando ampliar as liberdades das pessoas) pode potencializar ambas, no sentido de conquistarem a elaboração e a operacionalização de políticas públicas ainda mais efetivas, bem como de analisarem as ações em saúde da família (SF).

Contudo, é necessário considerar que as práticas discursivas de educação permanente da ESF não atingem toda a proposta da abordagem das capacitações. Para a abordagem das capacitações, a educação permanente seria um meio para o alcance das liberdades, e não um fim, uma vez que nem tudo é passível de resolução por meio das propostas de SF e, consequentemente, de sua prática discursiva principal. Isso não significa que tais propostas não tenham importância, mas que não se deve ignorar o fato de que aspectos estruturais, institucionais e políticos indispensáveis devem ser adequados, e que a melhoria de vida das pessoas (que, pela abordagem das capacitações, seria alcançada pelas liberdades) depende muito mais do que dos saberes, do conhecimento e da participação. Nesse sentido, Freire (1999) apontou que somente o conhecimento, sem as condições necessárias para ação, não basta.

Por outro lado, Freire (1983) também afirmou que a estrutura social, bem como a sua transformação, é obra dos homens, e que sua opção pela mudança ou pela "antimudança" determina tanto o seu papel quanto os seus métodos e as suas técnicas de ação. Esta perspectiva corrobora a afirmação de Sen (2000), a qual defende que a expansão das capacidades das pessoas de levarem o tipo de vida que valorizam, possui uma relação dupla no que diz respeito às políticas públicas: elas podem ser ampliadas pela política pública e também podem influenciar a orientação das ações, pelo uso das capacidades participativas da população. Assim sendo, mesmo limitada às necessárias estruturas e às instituições, a ação do homem (trabalhador social/trabalhador de saúde/usuário do sistema), comprometida com a mudança, tem grande potencial para gerar maior desenvolvimento social. Em outras palavras, a ESF e a educação permanente em saúde podem ser meios para a capacitação e para o alcance e desfrute de liberdades das pessoas, mesmo que não de todas. Não são suficientes para gerarem completo desenvolvimento social, mas são potencialmente fortes.

\section{Referências}

1. ALKIRE, S. The capability approach as a development paradigm? In: INTERNATIONAL CONFERENCE ON THE CAPABILITY APPROACH, 2003, Pavia. Anais... Pavia: [s.n], 2003. Disponível em: <http://www.capabilityapproach.com/pubs/461CAtraining_Alkire.pdf $>$. Acesso em: 03 jan. 2003.

2. ALMA-ATA. Declaração de Alma -Ata. In: CONFERÊNCIA INTERNACIONAL SOBRE CUIDADOS PRIMÁRIOS EM SAÚDE, 1978, Alma -Ata, Cazaquistão,. Anais... Alma-Ata: Cazaquistão, 1978.

3. ANDRADE, L. O. M. Sistema de Salud de Brasil: normas, gestion y financiamiento. São Paulo: Hucitec, 2002.

4. BANDEIRA, Pedro. Participação, articulação de atores sociais e desenvolvimento regional. Brasília: IPEA, 1999. (Textos para Discussão n ${ }^{\circ} 630$ ).

5. BERTALANFY, L. V. Teoria geral de sistemas. Brasília: INL, 1975.

6. BONASSA, E. C.; CAMPOS, C. V. A. Saúde mais perto: os programas e as formas de financiamento para os municípios. Brasília: Ministério da Saúde, 2001.

7. BRASIL. $\mathbf{8}^{\mathbf{a}}$ Conferência Nacional de Saúde: relatório final. Brasília: Ministério da Saúde, 1987. 
8. Agentes em Ação. Brasília: Ministério da Saúde, 1997a.

9. Constituição da República Federativa do Brasil - 1988. Brasília: Gráfica do Senado, 1988.

10. Dez anos de saúde da família no Brasil. Informe da Atenção Básica, Brasília, Ano V, n. 21, 2004a.

11 . I Seminário de Experiências Internacionais em Saúde da Família: relatório final. Brasília: Ministério da Saúde, 2002.

12. . II Mostra de Produções em Saúde da Família. Informe da Atenção Básica, Brasília, Ano V, Edição Especial, nov./dez. 2004c.

13. Lei n. 8080, de 19 de setembro de 1990. Dispõe sobre as condições para a promoção, proteção e recuperação da saúde, a organização e o funcionamento dos serviços correspondentes e dá outras providências. Brasília, 1990a.

14. Lei n. 9142, de 28 de dezembro de 1990. Dispõe sobre a participação da comunidade na gestão do Sistema Único de Saúde (SUS) e sobre as transferências intergovernamentais de recursos financeiros na área da saúde e dá outras providências. Brasília, 1990b.

15. Ministério da Saúde. Portal Saúde. Disponível em: <http:// www.saude.gov.br $>$. Acesso em: 25 abr. 2013.

16. Mostra Nacional de vivências inovadoras de gestão no SUS: Eixo 1: organização da atenção integral em saúde. Resumos dos trabalhos e grandes conversas. Brasília: Ministério da Saúde, 2006.

17. Norma Operacional da Assistência à Saúde. NOAS-SUS 01/01. Brasília: Ministério da Saúde, 2001a.

18. Portaria no $1886 /$ GM, de 18 de dezembro de 1997. Aprova as normas e diretrizes do Programa de Agentes Comunitários de Saúde e do Programa de Saúde da Família. Brasília, $1997 b$.

19. Portaria no 2448/GM, de 21 de outubro de 2011. Aprova a Política Nacional de Atenção Básica, estabelecendo a revisão de diretrizes e normas para a organização da Atenção Básica, para a Estratégia Saúde da Família (ESF) e o Programa de Agentes Comunitários de Saúde (PACS). Brasília, 2011

20. Programa Agentes Comunitários da Saúde (PACS). Brasília: Ministério da Saúde, 2001 b.

21. Revista Brasileira de Saúde da Família. Edição Especial. Brasília: Ministério da Saúde, 2004b.

22. Revista Brasileira Saúde da Família, Brasília, Ano 9, n. 17, p. 1-72, jan./mar. 2008a.

23. CALLAHAN, D. Equity, quality and patient rights: can they be reconciled? In.: LOLAS, F.; AGAR, L. (Ed.). Interfaces between bioethics and the empirical social sciences. Chile: World Health Organization/Panamerican Health Organization, 2002. p. 33-36.

24. CECCIM, R. B. Educação permanente em saúde: descentralização e disseminação de capacidade pedagógica na saúde. Ciência e Saúde Coletiva, v. 10, n. 4, p. 975-986, 2005.

25. COMIM, F. Operationalizing sen's capability approach. In: CONFERENCE ON JUSTICE AND POVERTY: examining Sen's Capability Approach, 2001, Cambridge. Anais... Cambridge: [s.n.], 2001. Disponível em: $<$ http://192.203.177.38/humanismocristiano/seminario_capability/pdf/7. pdf $>$. Acesso em: 25 abr. 2013.

26. COMIM, F.; QIZILBASH, M.; ALKIRE, S. (Eds.). The capability approach: concepts, measures and applications. Cambridge: Cambridge 
University Press, 2008.

27. COSTA, H. Carta às educadoras e aos educadores. In: BRASIL. Ministério da Saúde. Secretaria de Gestão do Trabalho e da Educação na Saúde. Departamento de Gestão da Educação na Saúde. A educação que produz saúde. Brasília: Ministério da Saúde, 2005.

28. DALLARI, S. G. Direito sanitário. São Paulo: USP/Centro de Estudos e Pesquisas de Direito Sanitário, 2008. Mimeo.

29. DATASUS. Cadernos de informações em saúde. Disponível em: <www. datasus.gov.br $>$. Acesso em: 30 abr. 2013.

30. DENEULIN, S. (Ed.). The human development and capabilities approach. London: Earthscan, 2009.

\section{FAIRCLOUGH, N. Discurso e mu- dança social. Brasília: Editora UNB, 2005.}

32. FERRAZ, S. F. S. Competências profissionais, mercado de trabalho e desenvolvimento local. In: ENCONTRO NACIONAL DA ASSOCIAÇÃO NACIONAL DOS PROGRAMAS DE PÓS GRADUAÇÃO EM ADMINISTRAÇÃO, 25., 2001, Campinas. Anais... Campinas: ANPAD, 2001a. 1 CD-ROM.

33. FIOCRUZ. Coleção VIII Conferência Nacional de Saúde: quadro geral do acervo. Disponível em: < http:// www.cocsite.coc.fiocruz.br/areas/dad/ guia_acervo/arq_pessoal/conferencia nacional.htm $>$. Acesso em: 30 abr. $20 \overline{13}$.

34. FLORES-CRESPO, P. Sen's human capabilities approach and higher education in Mexico. The case of the Technological University of Tula. In: CONFERENCE ON JUSTICE AND POVERTY: examining Sen's Capability Approach, 2001, Cambridge. Anais... Cambridge: [s.n.], 2001. Disponível em: <http://cfs.unipv.it/ca2004/ papers/flores $\% 20$ crespo.pdf $>$. Acesso em: 26 abr. 2013.

35. FREIRE, P. Educação e mudança. São Paulo: Paz e Terra, 1983.

36. Pedagogia do oprimido.

São Paulo: Paz e Terra, 1999.

37. FUKUDA-PARR, S. S.; KUMAR, $S$. Handbook of human development: concepts, measures and policies. Delhi: Oxford University Press, 2099.

38. FUKUDA-PARR, S. The human development paradigm: operationalizing Sen's ideas on development. Feminist Economics, v. 9, n. 2/3, p. 301-317, 2003.

39. KLERING, L. R.; SCHRÖEDER, C. S. Desenvolvimento de um ambiente virtual de aprendizagem à luz do enfoque sistêmico. Tecnologias de Administração e Contabilidade, Curitiba, v. 1, n. 2, p. 42-54, 2011.

40. Políticas e estratégias públicas municipais: novos desafios e perspectivas para o desenvolvimento local. Redes, Santa Cruz do Sul, v. 13, n. 2, p. 144-160, maio/ago. 2008.

41. KRUEL, A. J. Abrindo a porta para a dona saúde entrar: análise do significado do trabalho para agentes comunitários de saúde. 2006. Dissertação (Mestrado em Administração) - Programa de Pós Graduação em Administração, Escola de Administração, Universidade Federal do Rio Grande do Sul, Porto Alegre, 2006.

42. KUKLYS, W. Amartya sen's capability approach: theoretical insights and empirical applications. Berlin: Springer, 2005.

43. MENDES, A.; MARQUES, R. M. De olho no financiamento da atenção básica e no programa Saúde da Família. Revista Brasileira de Saúde da Família, Brasília, v. 5, n.7, p. 72-85, 2004.

44. MISOCZKY, M. C. Análise crítica do discurso: uma apresentação. Revista Eletrônica de Gestão Organizacional, v. 3, n. 2, 2005. 
45. MKANDAWIRE, T. Good governance: the itinerary of an idea. Development in practice, Routledge $\mathrm{Pu}-$ blishing, v. 17, n. 4-5, p. 679-681, 2007. 46. NOGUEIRA, R. P.; SILVA, F. B.; RAMOS, Z. V. O. A vinculação institucional de um trabalhador Sui Generis: o agente comunitário de saúde. Rio de Janeiro: Instituto de Pesquisa Econômica Aplicada, 2000.

47. NUSSBAUM, M. C. Capabilities as fundamental entitlements: sen and social justice. Feminist Economics, v. 9, n. 2/3, p. 33-59, 2003.

48. Women and human development: the capabilities approach. Cambridge: Cambridge University Press, 2000.

49. PEREIRA, L. C. B. Reforma do Estado para a cidadania: a reforma gerencial brasileira na perspectiva internacional. São Paulo: Editora 34, 2002.

50. PORSSE, M. C. S. A abordagem da capacitação como um modelo alternativo à nova administração pública para as ações estatais: um estudo de caso das políticas públicas dos municípios de Tupandi, Torres e Porto Alegre. 2006. Tese (Doutorado em Administração) - Programa de Pós-Graduação em Administração, Escola de Administração, Universidade Federal do Rio Grande do Sul, Porto Alegre, 2006.

51. PORSSE, M. C. S.; KLERING, L. R. A abordagem da capacitação como um modelo alternativo à Nova Administração Pública para as ações públicas: Um estudo de casos múltiplos. In: COLÓQUIO SOBRE PODER LOCAL, 10., 2006, Salvador. Anais... Salvador: [s.n.], 2006. 1 CD-ROM.

52. A abordagem das capacitações: um modelo alternativo para as ações públicas. Redes, v. 13, n. 1, p. 137-159, 2008.

53. Concepção moderna de desenvolvimento humano e social. Disponível em: <http://www.terragau- cha.com.br/artigo_lrk_e_mp_015.pdf $>$. Acesso em: 25 abr. 2013 .

54. RAWLS, J. Uma teoria da justiça. São Paulo: Martins Fontes, 1997.

55. RELATÓRIO DO DESENVOLVIMENTO HUMANO (UNDP). New York: Oxford University Press, 1997.

56. RIBEIRO, C.; MENDONÇA, P.; GUEDES, P. Modelos organizacionais para o desenvolvimento local sustentável e integrado. In: ENCONTRO NACIONAL DA ASSOCIAÇÃO NACIONAL DOS PROGRAMAS DE PÓS-GRADUAÇÃO EM ADMINISTRAÇÃO, 26., 2002, Salvador. Anais... Salvador: ANPAD, 2002. 1 CD-ROM.

57. RIBEIRO, E. C. de O.; MOTTA, J. I. J. Educação permanente como estratégia na reorganização dos serviços de saúde. Rio de Janeiro: Núcleo de Tecnologia Educacional para Saúde - NUTES/UFRJ, 2008. mimeo.

58. ROBEYNS, I. Sen's capability approach and gender inequality: selecting relevant capabilities. Feminist Economics, v. 9, n. 2/3, p. 61-92, 2003.

59. . The capability approach in practice. Journal of Political Philosophy, v. 14, n. 3, p. 351-376, 2006.

60. . The capability approach: a theoretical survey. Journal of Human Development, v. 6 , n. 1, p. 93-114, 2005.

61. SEN, A. A idéia de justiça. São Paulo: Companhia das Letras, 2011.

62. Capabilities, lists and public reasons: continuing the conversation. Feminist Economics, v. 10, n. 3, p. 77-80, 2004.

63. Desenvolvimento como

Liberdade. São Paulo: Companhia das Letras, 2000.

64. . Human rights and capabilities. Journal of Human Development, v. 6, n. 2, p. 151-66, 2005.

65. Well-being, agency and 
freedom: the dewey lectures 1984. Journal of Philosophy, v. 82, n. 4, p. 169-221, 1985.

66. SENNA, M. C. M. Equity and health policy: some reflections on the Family Health Program in Brazil. Cadernos de Saúde Pública, Rio de Janeiro, v. 18, 2002.

67. SOUZA, H. M. O programa de saúde da família no contexto do Sistema Único de Saúde. In: SEMINÁRIO DE EXPERIÊNCIAS INTERNACIONAIS EM SAÚDE DA FAMÍLIA - Relatório Final, 1, 2002, Brasília. Anais... Brasília: Ministério da Saúde, 2002.

68. STANFORD ENCYCOPEDIA OF PHILOSOPHY. The Capability Approach, 2011. Disponível em: $<$ http://plato.stanford.edu/entries/capability-approach/>. Acesso em: 27 abr. 2013.

69. TENDLER, J. Rural development without the urban-rural divide: descentralization, participation and other local things. Políticas Agrícolas, Taxco, n. especial, 1998 a.

70. Bom governo nos trópicos: uma visão crítica. Brasília: ENAP/ Revan, 1998b.

71. THOMAS, A. Development as practice in a liberal capitalist world. Journal of International Development, $\mathrm{n}$. 12, p. 773-787, 2000.

72. TUNES, E. et al. O trabalho do agente comunitário de saúde. Brasília: Ministério da Saúde, 1995. 